\title{
Prebiotic effects of pectooligosaccharides obtained from lemon peel on the microbiota from elderly donors using an in vitro continuous colon model (TIM-2)
}

Citation for published version (APA):

Miguez, B., Vila, C., Venema, K., Carlos Parajo, J., \& Luis Alonso, J. (2020). Prebiotic effects of pectooligosaccharides obtained from lemon peel on the microbiota from elderly donors using an in vitro continuous colon model (TIM-2). Food \& Function, 11(11), 9984-9999. https://doi.org/10.1039/d0fo01848a

Document status and date:

Published: 01/11/2020

DOI:

10.1039/dOfo01848a

Document Version:

Publisher's PDF, also known as Version of record

Document license:

Taverne

Please check the document version of this publication:

- A submitted manuscript is the version of the article upon submission and before peer-review. There can be important differences between the submitted version and the official published version of record.

People interested in the research are advised to contact the author for the final version of the publication, or visit the DOI to the publisher's website.

- The final author version and the galley proof are versions of the publication after peer review.

- The final published version features the final layout of the paper including the volume, issue and page numbers.

Link to publication

\footnotetext{
General rights rights.

- You may freely distribute the URL identifying the publication in the public portal. please follow below link for the End User Agreement:

www.umlib.nl/taverne-license

Take down policy

If you believe that this document breaches copyright please contact us at:

repository@maastrichtuniversity.nl

providing details and we will investigate your claim.
}

Copyright and moral rights for the publications made accessible in the public portal are retained by the authors and/or other copyright owners and it is a condition of accessing publications that users recognise and abide by the legal requirements associated with these

- Users may download and print one copy of any publication from the public portal for the purpose of private study or research.

- You may not further distribute the material or use it for any profit-making activity or commercial gain

If the publication is distributed under the terms of Article $25 \mathrm{fa}$ of the Dutch Copyright Act, indicated by the "Taverne" license above, 


\section{D) Check for updates}

Cite this: Food Funct., 2020, 11 9984

\title{
Prebiotic effects of pectooligosaccharides obtained from lemon peel on the microbiota from elderly donors using an in vitro continuous colon model (TIM-2) $\dagger$
}

\author{
Beatriz Míguez, ${ }^{a, b}$ Carlos Vila, a,b Koen Venema, ${ }^{c, d}$ Juan Carlos Parajóa,b and \\ José Luis Alonso iD *a,b
}

\begin{abstract}
The development of new prebiotics capable of modulating the gut microbiota in the elderly has become an area of great interest due to the particular vulnerability and frailty of this population. In the present work, mixtures of pectin-derived oligosaccharides (POS) were manufactured from lemon peel waste and evaluated for their capability to modulate the gut microbiota using, as inoculum, a pool of faeces from elderly donors. Both changes in the microbiota and the metabolic activity were assessed and compared with commercial fructooligosaccharides (FOS) and the standard ileal efflux medium (SIEM) using the TIM-2 in vitro colon model. POS fermentation led to similar or even better effects than FOS at phylum, family and genus levels. Higher increments in beneficial species such as Faecalibacterium prausnitzii and larger alpha diversity values were observed with POS in comparison with FOS and in some cases with SIEM. The PCOA analyses revealed that the microbial profiles resulting from POS and FOS bacterial fermentation were rather similar and differed from those observed after SIEM fermentation. Finally, although butyrate cumulative production was comparable among substrates, the highest short chain fatty acid (SCFA) and the lowest branched chain fatty acid (BCFA) cumulative production was observed in POS experiments. These results support the potential of pectin-derived oligosaccharides as prebiotic candidates targeting gut health in the elderly.
\end{abstract}

Received 14th July 2020, Accepted 29th September 2020 DOI: $10.1039 /$ dOfo01848a

rsc.li/food-function mated that in 2050 the population aged 60 years and older will account for 2 billion people. ${ }^{2}$ According to the European Commission, in Europe, people $\geq 65$ years have increased $2.9 \%$ with respect to the last decade, accounting for more than $20 \%$ of the total population. ${ }^{3}$

From a biological point of view, ageing implies diverse physiological changes that frequently are associated with negative health alterations, such as adverse changes in the gut microbial profile that, to date, have been related with several diseases beyond the gut. ${ }^{4,5}$ In this sense, the use of prebiotics is an interesting approach as they could be employed for dietary intervention to specifically modulate microbial imbalances in the elderly microbiota, thereby contributing to health improvement. ${ }^{4,6-9}$

The production of prebiotics (which are considered highvalue added products) from biomass could be a suitable approach for the management and valorization of by-products from the food industries. Citrus peel waste (a mixture of peels, seeds and pulps) is the major residue from the citrus processing industries; ${ }^{10}$ it represents around the $50 \%$ of the raw material and can be employed for the manufacture of pectinderived oligosaccharides (POS). ${ }^{11}$ These structurally complex 
oligosaccharides have shown to be better prebiotic candidates than the native pectins ${ }^{12,13}$ and several in vitro and in vivo studies support their prebiotic potential. ${ }^{14,15}$

Although POS have been already suggested as emerging prebiotics, ${ }^{14}$ the International Scientific Association for Probiotics and Prebiotics (ISAPP) ${ }^{16}$ did not include POS within the list of prebiotic candidates in their last expert consensus about prebiotics. ${ }^{16}$ Hence, further research is still needed to evaluate the effects of POS on the composition and metabolic activity of gut microbiota.

Among the in vitro techniques that can be used to assess the prebiotic potential of a given carbohydrate, dynamic in vitro systems are thought to simulate the in vivo conditions in a most reliable way than in vitro batch fermentation experiments. They are useful tools for screening purposes, particularly when combined with modern molecular techniques such as next generation sequencing of microbial communities, before performing in vivo studies, which would be more complex (i.e. ethical or financial).

The main objective of this work was to assess the prebiotic potential of a POS mixture obtained from lemon peel waste using the TIM-2 dynamic in vitro model of the proximal colon inoculated with elderly gut microbiota. The main effects driven by the POS fermentation in the abundances and diversity of the microbiota community, as well as cumulative production of both short chain fatty acids (SCFA) and branched chain fatty acids (BCFA) were evaluated and compared with fructooligosaccharides (FOS) as well as with the standard ileal efflux medium (SIEM). To the best of our knowledge, there are no in vitro studies performed in these types of dynamic models evaluating the prebiotic potential of POS mixtures from lemon peel waste in elderly microbiota.

\section{Materials and methods}

\subsection{Substrates}

2.1.1. Pectooligosaccharide mixtures (POS). Frozen lemon peel waste (LPW), provided by Indulleida S.A. Company (Lleida, Spain), was thawed at ambient temperature, homogenised in a single lot and processed as described by Gómez et al. (2013). ${ }^{17}$ Briefly, soluble compounds (mainly free sugars) were removed from the raw material by washing with water. Then, the insoluble fraction was treated with hot-compressed water under non-isothermal conditions, up to a maximum temperature of $160{ }^{\circ} \mathrm{C}$ in a stainless steel reactor with a working volume of $3.75 \mathrm{~L}$ (model 4842, Parr Instruments Company, Moline, Illinois) and at a liquid/solid ratio of 12 ( $\mathrm{kg}$ water per $\mathrm{kg}$ of dry-washed LPW). The liquid phase, containing the POS mixtures, was then refined using a combination of discontinuous diafiltration followed by a concentration step, employing a regenerated cellulose spiral wound membrane of $1 \mathrm{kDa}$ cut-off (TFF6, Millipore), according to the method developed and reported by Gómez et al. (2016). ${ }^{13}$ The purified POS were finally chemically characterised, freeze-dried and stored until use.
2.1.2. Commercial fructooligosaccharides

(FOS). Commercial fructooligosaccharides from chicory were supplied by Sigma-Aldrich Química S.A (Madrid, Spain) and included in the experimental work as a positive control.

2.1.3. Standard ileal efflux medium (SIEM). The standard ileal efflux medium (SIEM) was included in this work as a standard growth medium with comparative purposes. The composition of this medium simulates the material that passes from the small intestine to the colon in human individuals following typical Western diet food habits and it is specifically composed of complex carbohydrates (pectin, xylan, arabinogalactan, amylopectin and starch), proteins (bactopeptone and casein), minerals $\left(\mathrm{K}_{2} \mathrm{HPO}_{4}, \mathrm{NaCl}, \mathrm{CaCl}_{2}, \mathrm{FeSO}_{4}, \mathrm{MgSO}_{4}\right)$, vitamins (menadione, biotin, cobalamin, pantothenate, nicotinamide, para-aminobenzoic acid, thiamine), ox-bile, Tween 80, cysteine-HCl and haemin (all from Tritium Microbiology, Veldhoven, The Netherlands). ${ }^{18-20}$ The concentrations of pectin, xylan, arabinogalactan, and amylopectin in SIEM were slightly modified to $7.8 \mathrm{~g} \mathrm{~L}^{-1}$ (of each) and $64.5 \mathrm{~g} \mathrm{~L}^{-1}$ of starch for this study.

\subsection{Experimental set-up and performance}

The TIM-2 in vitro model of the proximal colon was developed and validated by TNO (The Netherlands Organisation for Applied Scientific Research) and integrates several computercontrolled technical components that allow the simulation of the proximal large intestinal environment. ${ }^{20,21}$ The model has been employed over the last two decades to assess the effects of a variety of compounds in both animal and human microbiota and consists of four individual units of $120 \mathrm{~mL}$ volume that work in parallel. A graphical scheme showing the particular features of this in vitro dynamic model as well as a complete description of its functioning can be found elsewhere. ${ }^{20,22,23}$

2.2.1. System feeding. For POS and FOS assays, two recipes were prepared by replacing the carbohydrates included in SIEM by either POS or FOS, respectively. After adjusting the $\mathrm{pH}$ of these solutions to 5.8, each mixture was homogenised, split into daily dosages (to ensure a homogeneous composition along the experiments) and frozen. This same procedure was followed for SIEM, which included the carbohydrates described in section 2.1.3. Before being added to the TIM-2 feeding syringes inside an anaerobic chamber (Bactron IV, Sheldon manufacturing, Cornelius, OR, USA), aliquots of all the substrates (corresponding to daily dosages) were thawed in a water bath at $37^{\circ} \mathrm{C}$.

2.2.2. Collection and processing of faecal samples. Six elderly volunteers ( 3 males and 3 females, age range 60-83 years old), who declared no gastrointestinal pathologies or food allergies, to follow a normal omnivorous diet, and not to use either laxatives, pre- or probiotics (excluding common fermented products) or antibiotics at least 2 months prior to stool collection, were recruited to donate the faecal samples employed in this study. The faecal samples were collected in clean plastic containers including an anaerobic gas generating sachet $\left(\right.$ AnaeroGen ${ }^{\mathrm{TM}}$, Oxoid, Cambridge, UK). Samples were 
delivered to the laboratory within 2 hours after collection and introduced into an anaerobic chamber (Bactron II, Shel-lab, USA) filled with a gas mixture consisting of $5 \% \mathrm{H}_{2}, 10 \% \mathrm{CO}_{2}$, and $85 \% \mathrm{~N}_{2}$. Samples from individual donors were prepared as described by Aguirre et al. (2015): ${ }^{24}$ faeces were individually weighed, mixed with a dialysate solution $(1: 1)$ and then glycerol was added to the mixture up to a final concentration of $12-15 \%(w / w)$. The faecal slurry was then homogenised with a blender, split into individual aliquots of the same volume and snap frozen with liquid $\mathrm{N}_{2}$ before storage at $-80^{\circ} \mathrm{C}$. A pool of the microbiota from the donors was prepared before initiating the TIM-2 experiments, where one tube from each donor was thawed in a water bath for 1 hour at $37^{\circ} \mathrm{C}$ to resuscitate the microbiota. ${ }^{25}$ Then, individual microbiota samples were transferred to an anaerobic cabinet (Bactron IV, Sheldon manufacturing, Cornelius, OR, USA), pooled and mixed with $50 \mathrm{~mL}$ of pre-reduced dialysate solution with vitamins as described previously. ${ }^{19}$

2.2.3. In vitro fermentation assays. The TIM-2 fermentation protocol followed in this study is shown in Fig. 1. Briefly, after filling the units with $60 \mathrm{~mL}$ of a dialysate solution with vitamins (composition details can be found elsewhere) ${ }^{26}$ and flushing the system with $\mathrm{N}_{2}$ for, at least, 3 hours (which continued throughout the test period to maintain anaerobic conditions), $55 \mathrm{~mL}$ of the standardised faecal pool (see above) were introduced into the system as inoculum. Subsequently, the SIEM feeding was initiated and maintained during 16 hours at a constant flow rate of $2.5 \mathrm{~mL} \mathrm{~h}^{-1}$ (adaptation period). Then, the feeding was stopped for 2 hours to allow the microbiota to ferment the residual carbohydrates remaining in the lumen (starvation period). Thereafter, samples corresponding to the initial time (fermentation time $t=0 \mathrm{~h}$, denoted as "t0h" in the manuscript) were taken and the syringes containing the daily dosages of each medium (POS, FOS or SIEM) were connected. One dosage containing $6.5 \mathrm{~g}$ of oligosaccharides (or total carbohydrates in SIEM) was fed per day at a constant rate during a period of 3 days. At $t=24,48$ and $72 \mathrm{~h}$ samples were collected from the lumen (the content inside the system) and dialysate (the liquid that permeates through the hollow fibre membranes inside the units and that contains the metabolites generated by the microbiota), immediately snapfrozen in liquid $\mathrm{N}_{2}$ and stored at $-80{ }^{\circ} \mathrm{C}$ until analysis. At $t=$ $24 \mathrm{~h}$ and $t=48 \mathrm{~h}$, a total of $25 \mathrm{~mL}$ (samples + plus additional volume) of lumen content was removed from the system for simulating the movement of content from proximal to distal colon. Moreover, the $\mathrm{pH}$ of the lumen was maintained at 5.8 by $\mathrm{NaOH}$ addition during the experiment duration. All of these experiments were carried out in duplicate.

\subsection{Analytical methods}

2.3.1. POS chemical characterisation. POS mixtures were chemically characterised following the procedure described by Gómez et al. in 2013. ${ }^{17}$ In short, a sample of freeze-dried POS was diluted with distilled water and one aliquot was filtered through a $0.45 \mu \mathrm{m}$ cellulose acetate membrane and analysed by HPLC (1260 Agilent chromatograph provided with an refractive index (RI) detector, Agilent Technologies, Santa Clara, CA, USA) to determine its content of monosaccharides, acetic acid and galacturonic acid, employing an Aminex HPX-87H column (BioRad, Hercules, CA) thermostated at $50{ }^{\circ} \mathrm{C}$ with $\mathrm{H}_{2} \mathrm{SO}_{4}$ $0.003 \mathrm{M}$ as the mobile phase at a flow rate $=0.6 \mathrm{~mL} \mathrm{~min}^{-1}$ and the temperature of the RI detector being $35^{\circ} \mathrm{C}$. For the determination of the oligomer content, and due to the complexity of the POS mixture, two protocols were carried out: (i) oligogalacturonides were hydrolysed by using commercial endopolygalacturonase and cellulose preparations (Viscozyme L and Celluclast 1.5 L, respectively, from Novozymes, Bagsvaerd, Denmark); and (ii) neutral oligomers were broken into mono-

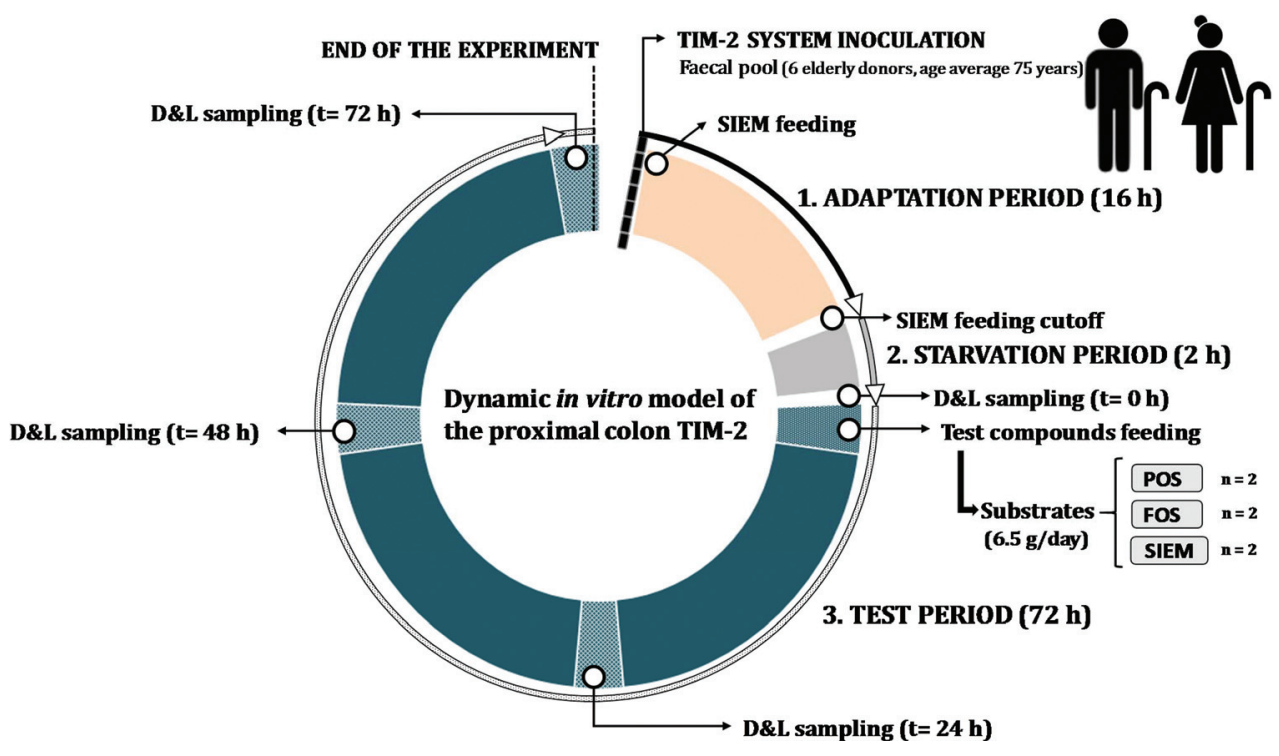

Fig. 1 Time-line of in vitro experiments performed in the model of the proximal colon (TIM-2). D, dialysate; FOS, fructooligosaccharides; L, lumen; POS, pectooligosaccharides; SIEM, standard ileal efflux medium. 
saccharides by acid hydrolysis carried out for $20 \mathrm{~min}$ in an autoclave at $121{ }^{\circ} \mathrm{C}$ using a final $\mathrm{H}_{2} \mathrm{SO}_{4}$ concentration of $4 \%$. Both hydrolysates were then analysed by HPLC as described above and the oligomer content was calculated by the increment in the respective monomer concentration observed after hydrolysis. Galactose peaks might include also small traces of xylose. All analyses were done in triplicate.

2.3.2. Changes in the bacterial population and its metabolic activity. Bacterial populations were identified and quantified following the procedures described by Cuevas-Tena et al. (2019). ${ }^{19}$ In short, ZYMO research kits (supplied by BaseClear, Leiden, The Netherlands) were employed for genomic DNA isolation before 16S rRNA gene PCR amplification (V3 and V4 regions). The Illumina MiSeq and BCL2FASTQ pipeline version 1.8.3. (both Illumina, Eindhoven, The Netherlands) were used for sequencing and sequence conversion into FASTQ files, respectively (quality cut-off was based on the Phred quality score). The QIIME software package (1.9.0) was employed for the microbiota analyses. ${ }^{27}$

The production of acetate, butyrate, propionate, formate, caproate, lactate, succinate, valerate, iso-butyrate and iso-valerate in samples from lumen and dialysate was determined by ion exclusion chromatography (chromatograph model 883, IC, Metrohm, Switzerland) using a Transgenomic IC Sep ICE-ION-300 column by injecting $10 \mu \mathrm{L}$ of samples, previously centrifuged (14000 rpm) and diluted in $1.5 \mathrm{mM} \mathrm{H}_{2} \mathrm{SO}_{4}$ mobile phase and using a flow rate of $0.4 \mathrm{~mL} \mathrm{~min}^{-1}$ and a column temperature of $65{ }^{\circ} \mathrm{C}$, as described by Cuevas-Tena et al. (2019). ${ }^{19}$ These analyses were carried out by Brightlabs (Venlo, The Netherlands).

The data corresponding to fermentation experiments using SIEM (see section 2.1.3) were already published by Míguez et al. (2020), ${ }^{28}$ and were included in this work for comparative purposes (same elderly gut microbial pool and experimental protocols were employed).

\subsection{Statistical analysis and data presentation}

All the substrate experiments were performed in duplicate. Data for the baseline microbiota (toh) correspond to the average of 5 experiments (an outlier corresponding to one of the SIEM experiments was discarded in these analyses). R software (3.6.2) was used to identify possible correlations (Spearman) between the cumulative organic acid productions and substrates, as well as between acid production and the relative abundances (RA) of particular operational taxonomic units (OTUs). The rho values indicate whether the correlation is positive $($ rho $>0$ ) or negative $($ rho $<0)$. $\mathrm{R}$ software was also employed to analyse the differences among RA (at phylum, family and genus levels) as a function of the substrate used (including as a separated group the baseline microbiota composition, t0h), which were assessed using the non-parametric Kruskal-Wallis test corrected for multiple comparisons by false discovery rate (FDR) followed by Dunn post hoc tests (corrected by Holm's method) when significant differences were found. Differences were considered significant when $q$ values (adjusted $p$ values) were lower than 0.05 for Kruskal-Wallis tests and $p$ adjusted values were lower than 0.05 for Dunn tests. In addition, $\mathrm{R}$ was utilised to perform parametric contrasts when assumptions of normality and variances homogeneity were fulfilled, namely one-way ANOVA and Tukey's multiple comparisons post hoc tests, where differences were considered significant at $p<0.05$ in both cases. One-way ANOVA comparisons included those performed to examine the differences in richness and diversity parameters obtained for toh $(n=5)$ and for $t=72 \mathrm{~h}(\mathrm{t} 72 \mathrm{~h})$ for each substrate $(n=2)$ measured at 21400 seqs per sample as well as the presence of dissimilarities in these parameters among $t=24,48$ and $72 \mathrm{~h}$ for each carbohydrate experiment. Besides, differences in organic acid production (molar ratios and mmol) after $72 \mathrm{~h}$ of fermentation were assessed following this procedure.

Linear discriminant analysis effect size (LEfSe) ${ }^{29}$ was carried out using Galaxy online software (https://huttenhower. sph.harvard.edu/galaxy) to identify OTUs which consistently differed among substrates, based on the RA found between $t=$ $24 \mathrm{~h}(\mathrm{t} 24)$ and $t=72 \mathrm{~h}(\mathrm{t} 72 \mathrm{~h})$. These analyses were complemented with random forest analyses, which were performed online in MetagenAssist for microbiota feature identification based on their RA between t24h and t72h (http://www.metagenassist. ca/METAGENassist/faces/Home.jsp). Besides, weighted and unweighted UniFrac principal coordinate analyses were performed using QIIME.

\section{Results and discussion}

\subsection{POS chemical composition}

The chemical composition of the POS employed as substrates in this work is shown in Table 1. As it can be seen, this mixture was mostly composed of acidic oligogalacturonides $(44.36 \% \mathrm{w} / \mathrm{w})$, arabinooligosaccharides $(16.86 \% \mathrm{w} / \mathrm{w})$ and galactooligosaccharides $(11.64 \% \mathrm{w} / \mathrm{w})$, which is in accordance with data reported previously. ${ }^{13}$ Detailed information about the chemical structure of this POS mixture (including DP distribution, degree of acetylation and degree of methylation) can be found in the aforementioned article. ${ }^{13}$

Table 1 Average $( \pm S D ; n=3)$ chemical composition of POS $(\% w / w$, oven-dry basis). AcO, acetyl substituents in oligomers; Ara, arabinose; AraOS, arabinooligosaccharides; GalOS, galactooligosaccharides; Glc, glucose; GlcOS, glucooligosaccharides; OGalA, oligogalacturonides; ONVC, other non-volatile compounds; RhaOS, rhamnooligosaccharides

\begin{tabular}{lll}
\hline Component & & $\%(\mathrm{w} / \mathrm{w})$ \\
\hline Monosaccharides & Glc & $0.85 \pm 0.00$ \\
& Ara & $0.10 \pm 0.00$ \\
Oligosaccharides & OGalA & $44.36 \pm 0.86$ \\
& GlcOS & $3.98 \pm 0.13$ \\
GalOS & $11.64 \pm 0.20$ \\
RhaOS & $1.84 \pm 0.03$ \\
& AraOS & $16.83 \pm 0.15$ \\
& AcO & $3.16 \pm 0.39$
\end{tabular}




\subsection{Baseline community structure of the faecal pool from elderly donors}

Previous studies have demonstrated that pooling faecal samples from several donors to obtain an inocula for in vitro experiments is an adequate approach for this type of fermentation study as it does not result in an anomalous microbiota or metabolic activity in comparison with that from individual donors. $^{24,25}$

When studying the effects of different carbohydrates in a specific group of population for comparative purposes, this collection and standardization procedure allows the use of the same active and well-preserved inocula in all the assays which, due to technical issues and/or the duration of the in vitro experiments, have to be performed over an extended period of time (several weeks and, even, months). In addition, as the same baseline microbiota is used along the experimental setup, the possibility of high inter-individual variations that could make it difficult to extract solid conclusions is avoided, as the microbiota from elderly donors has shown an extreme variability $^{30}$ and experiments performed with ex-germfree mice colonized with human microbiota have demonstrated the existence of important differences in the microbial responses of different microbiota profiles even when consuming the same diet. ${ }^{31}$

The main microbial communities found at both phylum and family levels in the faecal pool from elderly donors after the adaptation and starvation periods (t0h, $n=5$ ) are included in Table 2. The most prevalent phyla found were Firmicutes and Bacteroidetes (accounting for more than the $90 \%$ of the total identified microbiota) followed by Actinobacteria, a distribution pattern that was in accordance with that usually found within the human gut microbiota ${ }^{32}$ and, at the family level, the most abundant ones were Ruminococcaceae, Lachnospiraceae and Bacteroidaceae. The aforementioned bacterial RA were in accordance with those published by Ntemiri et al. $(2017)^{33}$ for three healthy elderly donors of the same average age (75 years), which reported a $68 \%$ of Firmicutes and a $22.5 \%$ of Bacteroidetes. Nevertheless, these authors found higher levels for Lachnospiraceae (37\%) and lower levels for Ruminococcaceae (14\%) families, although the sum of the percentages for both families observed in this work is within the range of $50-70 \%$ reported for faecal samples from healthy donors. ${ }^{34}$ In addition, a very similar profile was also described by Doo et al. $(2019)^{35}$ for healthy elderly donors aged 71-78 years. These observations corroborate that pooling the faecal samples did not result in unusual microbial abundances.

On the other hand, at the genus level, 90 OTUs were identified, from which 39 represented more than $98 \%$ of the total microbiota. As it can be seen in Fig. 2, the six dominant genera found in this baseline microbiota corresponded to an unknown genus from Ruminococcaceae family (14.72 $\pm 1.16 \%)$, Ruminococcus $(13.7 \pm 2.92 \%)$, Bacteroides (7.99 $\pm 1.98 \%)$, an unidentified genus within Lachnospiraceae family $(7.37 \pm 1.29 \%)$, Blautia $(7.25 \pm 0.5 \%)$ and Prevotella $(6.62 \pm 2.5 \%)$. Moreover, low standard deviations were observed among experiments in the bacterial communities found at toh, which confirmed the reliability of the standard working procedures of the continu-

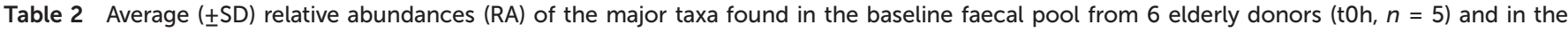

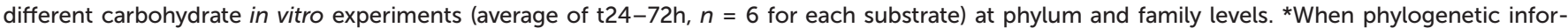

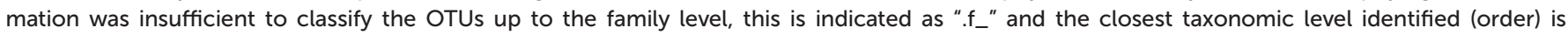

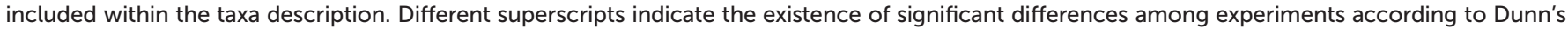

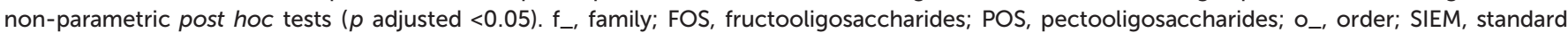
ileal efflux medium

\begin{tabular}{|c|c|c|c|c|c|}
\hline & & toh & POS & FOS & SIEM \\
\hline \multirow[t]{7}{*}{ Phylum } & Firmicutes & $70.82(1.95)^{b}$ & $60.16(3.15)^{\mathrm{ab}}$ & $51.52(5.12)^{\mathrm{a}}$ & $44.47(14.36)^{\mathrm{a}}$ \\
\hline & Bacteroidetes & $19.85(1.31)^{b}$ & $33.34(3.22)^{\mathrm{ab}}$ & $41.53(5.09)^{\mathrm{a}}$ & $25.26(8.56)^{\mathrm{b}}$ \\
\hline & Actinobacteria & $6.89(0.91)^{b c}$ & $3.21(0.77)^{\mathrm{a}}$ & $5.10(0.89)^{\mathrm{ab}}$ & $29.05(13.52)^{\mathrm{c}}$ \\
\hline & Euryarchaeota & $0.89(0.28)^{c}$ & $0.52(0.16)^{\mathrm{ac}}$ & $0.29(0.15)^{\mathrm{ab}}$ & $0.14(0.12)^{\mathrm{b}}$ \\
\hline & Proteobacteria & $0.54(0.22)$ & $1.38(0.68)$ & $0.71(0.24)$ & $0.57(0.62)$ \\
\hline & Other phyla & $0.16(0.05)$ & $0.10(0.06)$ & $0.05(0.04)$ & $0.01(0.01)$ \\
\hline & Unassigned & $0.86(0.18)$ & $1.28(0.10)$ & $0.81(0.12)$ & $0.50(0.23)$ \\
\hline \multirow[t]{12}{*}{ Family } & Ruminococcaceae & $32.53(2.46)^{b}$ & $30.42(1.05)^{\mathrm{ab}}$ & $17.43(4.94)^{\mathrm{a}}$ & $26.63(10.32)^{\mathrm{ab}}$ \\
\hline & Lachnospiraceae & $24.59(2.31)^{\mathrm{b}}$ & $17.80(1.66)^{\mathrm{ab}}$ & $9.37(1.61)^{\mathrm{a}}$ & $7.71(6.30)^{a}$ \\
\hline & Bacteroidaceae & $7.99(1.98)^{b}$ & $1.99(1.76)^{\mathrm{ab}}$ & $6.83(7.92)^{\mathrm{ab}}$ & $0.85(0.83)^{\mathrm{a}}$ \\
\hline & Prevotellaceae & $6.62(2.50)^{c}$ & $28.60(2.12)^{a b}$ & $33.66(9.90)^{\mathrm{a}}$ & $14.68(8.53)^{b c}$ \\
\hline & o_Clostridiales. $f_{-}{ }^{*}$ & $6.05(0.69)^{\mathrm{ab}}$ & $3.34(1.24)^{\mathrm{a}}$ & $3.03(2.18)^{\mathrm{ab}}$ & $3.31(1.92)^{b}$ \\
\hline & Coriobacteriaceae & $4.05(0.54)^{\mathrm{ab}}$ & $1.72(0.64)^{\mathrm{a}}$ & $4.47(0.68)^{\mathrm{ab}}$ & $17.91(11.28)^{b}$ \\
\hline & Clostridiaceae & $3.60(0.47)^{\mathrm{ab}}$ & $3.74(0.83)^{\mathrm{a}}$ & $3.66(0.37)^{\mathrm{ab}}$ & $1.45(1.41)^{\mathrm{b}}$ \\
\hline & o_Bacteroidales.f_S24.7 & $2.90(0.78)^{b}$ & $1.20(0.71)^{\mathrm{ab}}$ & $0.63(0.51)^{\mathrm{a}}$ & $4.98(4.04)^{\mathrm{b}}$ \\
\hline & Bifidobacteriaceae & $2.81(0.44)^{b c}$ & $1.49(0.28)^{\mathrm{ab}}$ & $0.63(0.26)^{\mathrm{a}}$ & $11.12(9.95)^{\mathrm{c}}$ \\
\hline & Veillonellaceae & $1.62(0.18)^{b}$ & $2.34(0.45)^{\mathrm{ab}}$ & $8.01(3.09)^{\mathrm{a}}$ & $1.84(2.56)^{\mathrm{b}}$ \\
\hline & Other families & $6.38(0.38)$ & $6.07(1.03)$ & $11.46(5.73)$ & $9.01(6.66)$ \\
\hline & Unassigned & $0.86(0.18)$ & $1.28(0.10)$ & $0.81(0.12)$ & $0.50(0.23)$ \\
\hline
\end{tabular}



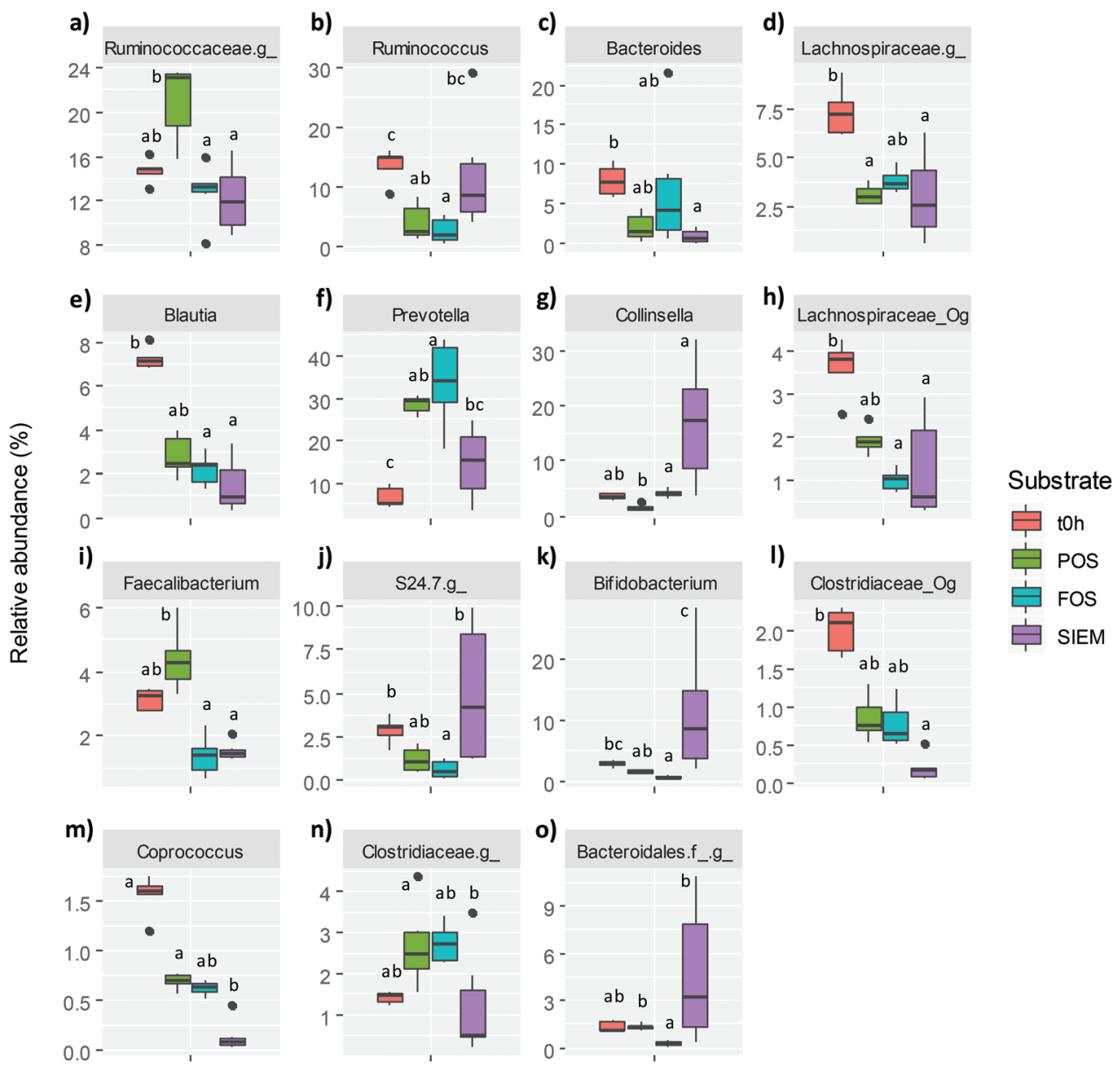

Genus

Fig. 2 Boxplots of relative abundances (\%) of highest abundant genera (according to the baseline microbiota, t0h) from elderly donors showing significant differences among groups (Kruskal-Wallis $q$ values $<0.05$ ). The boxplots include data corresponding to tOh $(n=5)$ and carbohydrate experiments (average of $t=24 \mathrm{~h}-72 \mathrm{~h}, n=6$ for each substrate). Groups that share a letter do not significantly differ according to Dunn's non parametric post hoc test (significance at $p<0.05$ ). When the taxonomic name is designated as "f_" or "o_", it denotes an unknown genus within the indicated family or within a given order, respectively. The notation "Og" indicates "other genus" within the mentioned family if two unknown genera are present within that family. FOS, fructooligosaccharides; POS, pectooligosaccharides; SIEM, standard ileal efflux medium.

ous TIM-2 in vitro model (despite the multiple variables involved in its operation) and therefore the shifts observed in this work can be attributed only to the substrate fermentation.

\subsection{Changes in gut microbiota after in vitro fermentation}

Table 2 also summarizes the relative abundances (measured as percentages) at phylum and family levels observed during the fermentation experiments.

In order to assess the significant microbial modulations after the carbohydrate administration, Kruskal-Wallis tests were carried out to compare the RA observed at toh and those measured during the test period (average of t24h-t72h, $n=6$ for each substrate).

Significant differences among toh and substrate experiments were found for all phyla except for Proteobacteria. When comparing substrates, POS and FOS, showed no significant differences with respect to the major phyla, showing POS and FOS statistically comparative shifts whereas SIEM promoted different changes in comparison with POS or FOS in Actinobacteria RA (see Table 2). This is a positive result as Actinobacteria numbers were found to be decreased in the elderly. ${ }^{4}$

The most significant changes regarding the toh RA were a decrease in Firmicutes and Euryarchaeota using FOS and SIEM, and a decrease in Actinobacteria levels with POS (although not significantly different from that observed with FOS). In addition, FOS intervention promoted a marked increase in Bacteroidetes with respect to toh, an effect that has also been observed after FOS in vitro fermentation using immobilised elderly faecal microbiota. ${ }^{35}$

Similarly to that observed at the phylum level, POS and FOS experiments did not differ significantly with regard to the RA of the main families considered, where the most remarkable effect observed for both substrates was a significant rise in the 
Prevotellaceae family. Nevertheless, compared to the baseline levels, the most significant shifts were observed with FOS (namely a decline in Ruminococcaceae, Lachnospiraceae and Bifidobacteriaceae as well as an increase in Veillonellaceae RA).

The main differences with respect to toh observed with SIEM corresponded to a decrease in Lachnospiraceae and Bacteroidaceae levels.

Focusing on the genus level, a total of 107 OTUs were identified, from which 60 corresponded to RA values across groups greater than $0.01 \%$. This value was used as a cut-off level to perform the Kruskal-Wallis tests to determine the significant differences among the toh and carbohydrate experiments as well as among substrates (as above, considering the averages of values at $\mathrm{t} 24 \mathrm{~h}-\mathrm{t} 72 \mathrm{~h}, n=6$ for each substrate). Up to 50 genera showed significant differences and the 15 genera accounting the largest RA (based on toh values) are represented in Fig. 2.

On the other hand, discriminant analysis (LDA) effect size (LEfSe) was applied to the experimental data (t24-t72h) in order to identify OTUs which consistently differentiated the microbial profiles. Fig. 3 shows the taxa that were found as indicators for the three substrates (3a), as well as the highest LDA scores found at the genus level (3b). Besides, random forest (RF) analysis based on the normalised abundances ( $\mathrm{t} 24-$ $\mathrm{t} 72 \mathrm{~h}$ ) was also applied to determine the most important features observed for each substrate (Fig. 4 and Fig. S1†). The most relevant variations found among substrate groups are discussed below.

Although FOS are recognised as especially bifidogenic prebiotics, and that certain enzymes with prevalence in Bifidobacterium spp. can degrade this substrate, ${ }^{16}$ in this work no strong bifidogenic effect was observed for this substrate (Fig. 2k), even though other studies reported bifidogenic activity in vitro for FOS using elderly microbiota as inocula. ${ }^{35}$ Bifidobacteria percentages observed with either POS or SIEM did also not differ significantly from the toh levels, however, SIEM lead to the highest Bifidobacterium RA (Fig. 2k). Literature shows variable results about the effects of pectin derived products on this genus: the fermentation of some pectin rich substrates such as passion fruit peels also showed lower levels of bifidobacteria in comparison with SIEM ${ }^{36}$ whereas POS obtained from orange and lemon peel have shown previously bifidogenic effect in vitro using inocula from healthy adults. ${ }^{13,37}$

The effect of SIEM on Collinsella was very similar to that observed for Bifidobacterium, where a high variation among the RA found throughout the different sampling times was found. In fact, LEfSe analyses signalled these two genera (Bifidobacterium and Collinsella) as features for SIEM experiments (Fig. 3), an observation that was also supported by RF analyses which indicated, in particular, increases in the species Bifidobacterium adolescentis (Fig. 4) and Collinsella aerofaciens (Fig. S1i†). Lower Bifidobacterium levels have been detected in the elderly, ${ }^{38}$ and specifically, Bifidobacterium adolescentis has been reported as one of the most commonly found Bifidobacterium species in this population (average age $=$ 84 years), ${ }^{39}$ with greater abundances than those observed in younger elderly (average age $=62$ years). ${ }^{7}$

Relative abundances of Coprococcus (Fig. 2m), which has been reported to be more abundant in community-dwelling elderly subjects, ${ }^{40}$ were similar in POS and FOS experiments, which did not differ significantly with respect to the levels a)

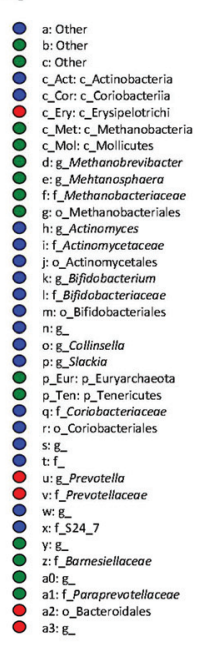

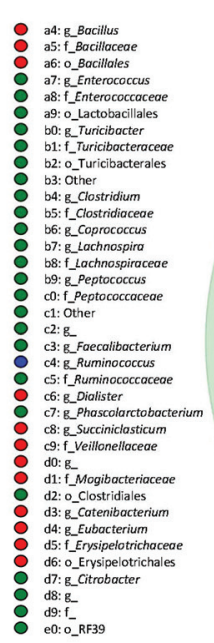

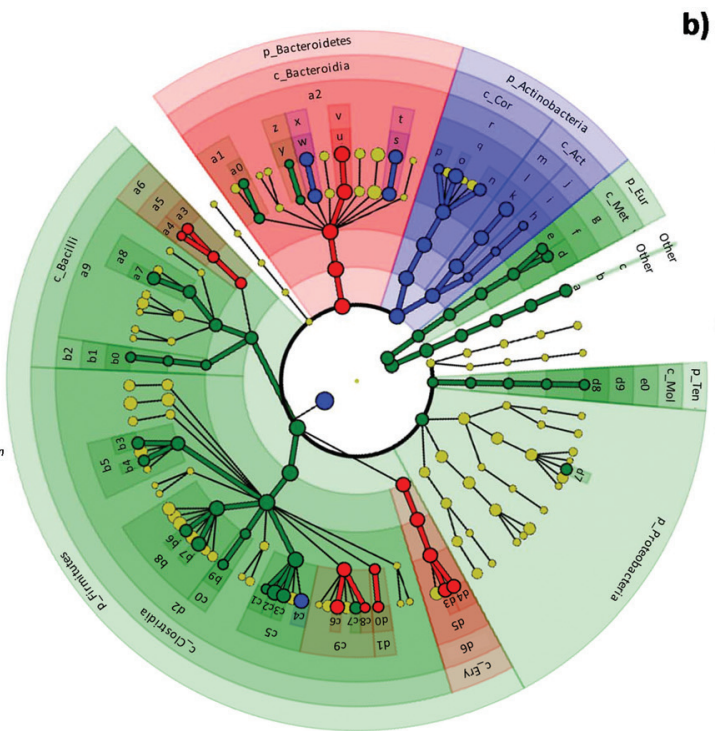

b)

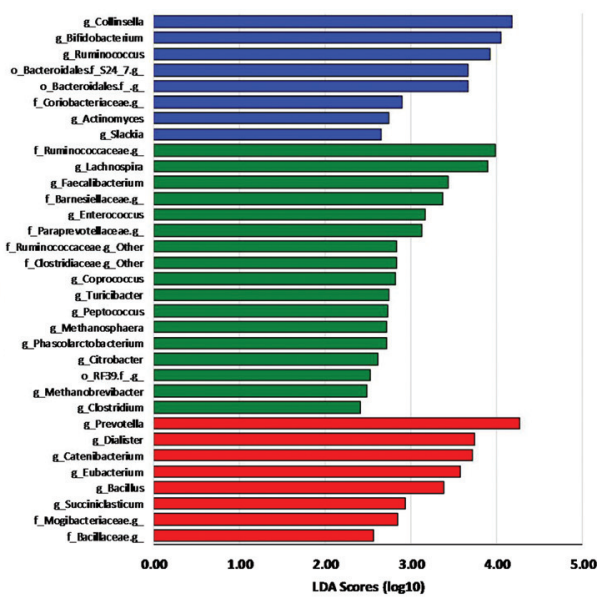

Fig. 3 Linear discriminant analysis effect size (LEfSe) results: (a) Cladogram representing the different distribution of microbial taxa among experiments, (b) LDA scores found at the genus level. Fermentation times (t24-t72h) of the different test products were included to determine specific genera associated with particular carbohydrate in vitro interventions. The notations "f_", "g_" and "other" indicate insufficient phylogenetic information to classify the corresponding OTU up to the indicated level. FOS, fructooligosaccharides; POS, pectooligosaccharides; SIEM, standard ileal efflux medium. Colour codes represent the $\square$ FOS $\square$ POS $\square$ SIEM different experiments. 
a)

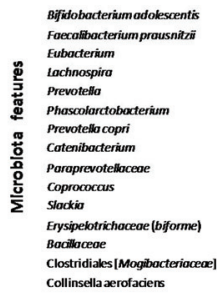

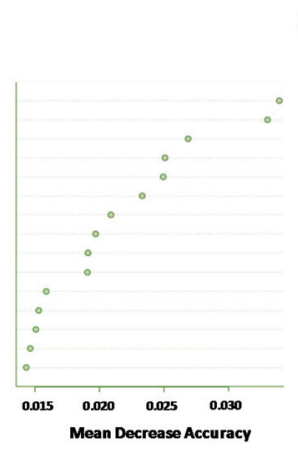

b)
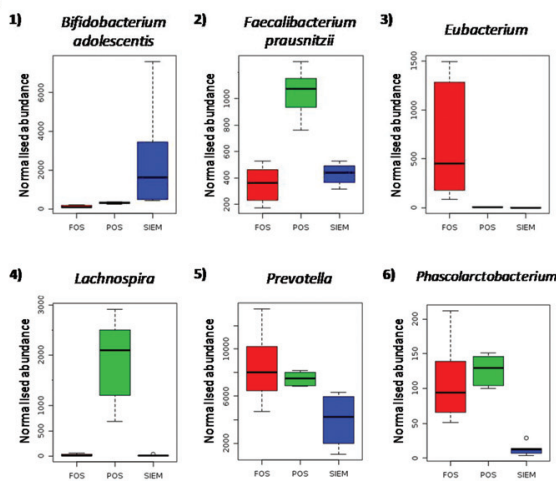

Fig. 4 Random forest analysis results, where data from t24-t72h for each experiment were included: (a) main 15 features found based on mean decrease accuracy, and (b) boxplots of normalized abundances of the 6 main features found. FOS, fructooligosaccharides; POS, pectooligosaccharides; SIEM, standard ileal efflux medium.

measured in toh samples, while being significantly lowered when using SIEM as the substrate, an effect also observed for Phascolarctobacterium. Low normalised abundances were found for both Coprococcus and Phascolarctobacterium and, according to RF, low values of both genera were selected as features for SIEM experiments (Fig. 4 and Fig. S1d †). In addition, the stimulation of these genera was associated with POS by LEfSe (Fig. 3). This is a positive outcome as some species as Coprococcus eutactus and Coprococcus comes are known as butyrate producers ${ }^{41}$ and this genus was observed to be depleted in depression patients ${ }^{42}$ depression being one of the most common mental diseases in the elderly. ${ }^{43}$

Regarding Lachnospira and Faecalibacterium, both LEfSe and $\mathrm{RF}$ were in concordance in pointing out these genera as discriminant (Fig. 3) and feature (Fig. 4) for POS experiments, respectively. Markedly, RF analysis indicated the species Faecalibacterium prausnitzii (Fig. 4), bacteria that have been suggested as an indicator of intestinal health, ${ }^{44}$ as the second most important feature for classifying the samples. Although the increase of Lachnospira using pectin as a carbohydrate source has been related to metabolite cross-feeding due to their apparent incapacity for pectin degradation, ${ }^{45}$ this genus has been reported to be stimulated by pectin rich materials such as orange bagasses ${ }^{36}$ and also by a large range of pectins with a variety of structures and compositions, obtained from orange, lemon, sugar beet and lime. ${ }^{45}$ In addition, F. prausnitzii was previously reported to be able to grow using citrus pectin as the substrate, ${ }^{46}$ as it can use galacturonic acid. ${ }^{47}$ This was confirmed in the current study taking into account the increase of this genus abundance and the composition of the POS mixture used which contains up to $44.36 \%$ (w/w) of galacturonic acid (Table 1$)$. Besides, a reduction was observed in $F$. prausnitzii abundance with respect to toh when using SIEM, which is in agreement with the findings reported by the aforementioned study ${ }^{47}$ regarding the inability or low capacity of this species to grow using arabinogalactan, xylan or soluble starch, which are the main components in SIEM. The ability of a substrate to promote the growth of this particular genus/species is strongly desirable as diminished abundances of this genus have been reported in the elderly ${ }^{38}$ (even higher in hospitalised elderly ${ }^{48}$ and because $F$. prausnitzii has demonstrated anti-inflammatory properties ${ }^{49}$ that might have the potential in counteracting elderly characteristic inflammation processes ${ }^{50}$ through diet.

Both Catenibacterium and Eubacterium were associated with FOS experiments according to LEfSe (Fig. 3), and RF (Fig. 4 and Fig. S1b $\dagger$ ). Species of both genera have been shown to produce butyrate which could positively affect the elderly gut health. ${ }^{51-53}$

The RA of Prevotella significantly increased with POS and FOS with respect to the baseline microbiota levels (Fig. 2f). However, LEfSe signalled this genus as the indicator with the highest LDA score for FOS fermentation only (Fig. 3). In addition, RF indicated Prevotella as a feature for FOS experiments, showing higher normalized abundances of this genus (Fig. 4b), although lower normalised abundances of the particular species Prevotella copri were observed with SIEM (Fig. S1a †). Prevotella has been linked with diets with a high content of carbohydrates ${ }^{54}$ and an increase in this genus (and also in the Prevotellaceae family, as observed with both POS and FOS, see Table 2) can be considered a promising outcome for a prebiotic targeting the elderly population because decreases of these bacterial communities have been associated with Parkinson's disease ${ }^{55}$ (which has a great impact in elderly adults $)^{56}$ and Prevotella enriched enterotypes have shown to be less common among elderly individuals accounting for high constipation severity scores ${ }^{55}$ (the elderly being a population prone to constipation). ${ }^{57}$

Dialister has been selected by LEfSe (Fig. 3) as a discriminant genus for FOS experiments. This genus showed a significant rise with respect to toh values with FOS but not with POS (data not shown). Dialister is known to produce propionate, ${ }^{58}$ which is in agreement with the higher propionate ratios found upon feeding FOS (see section 3.5 below).

The RA of Ruminococcus (from Ruminococcaceae family) significantly decreased with POS and FOS with respect to the 
baseline microbiota, while levels were comparable to the toh values with SIEM and no significant differences were observed between SIEM and POS (Fig. 2b). This genus was signalled by LEfSe as an indicator for SIEM (Fig. 3). Furthermore, Ruminococcus is also known as a butyrate-producing genus which has been shown to be reduced in the elderly. ${ }^{7}$

It is noteworthy to mention that an unknown genus also from the Ruminococcaceae family showed significantly higher values with POS in comparison with FOS or SIEM, although this rise was not significant with respect to toh according to Kruskal-Wallis (Fig. 2a). The observed increase is in accordance with LEfSe results, where this unidentified genus reached the highest LDA scores for POS experiments (Fig. 3).

LEfSe analysis also linked the genus Enterococcus with POS fermentation (see Fig. 3), whose RA significantly increased upon POS fermentation (data not shown).

Two unknown genera from the family Clostridiaceae showed almost opposite effects after fermentation (Fig. 2). Higher levels compared to baseline were found with POS and FOS for Clostridiaceae_g, whereas lower levels were observed for Clostridiaceae_Og using these substrates.

Finally, FOS and SIEM significantly decreased the RA of Blautia while POS experiments led to values which did not significantly differ from the baseline microbiota (Fig. 2). High abundances of Blautia were reported to be a strong indicator of gut health and, in particular, Blautia coccoides has been mentioned as a target for improving the elderly microbiota as it was observed to be reduced in this population and to enhance the status of gut mucosa. ${ }^{7}$

\subsection{Changes in bacterial alpha and beta diversity assessment}

For the assessment of both richness and evenness of the microbial communities, which must be taken into consideration when measuring microbial diversity for sample comparison, ${ }^{59}$ several bacterial diversity-related metrics have been examined. Observed OTUs, phylogenetic diversity (whole tree),
Chao1 Index and Shannon Index, were calculated at the start (toh) and along the in vitro assays with the different carbohydrates, using the RA of the identified OTUs rarefied at 21400 sequences per sample. Fig. 5 shows the values obtained for these parameters at toh $(n=5)$ and after $72 \mathrm{~h}$ of in vitro fermentation of each substrate ( $n=2$ per substrate) and rarefaction curves showing changes over time are included in the ESI (Fig. S2-S4†). The fermentation of carbohydrates resulted in a significant decrease in all alpha diversity metrics after $72 \mathrm{~h}$ in comparison with toh values. A similar effect was observed in Chao1 index after $72 \mathrm{~h}$ of in vitro fermentation in the TIM-2 system by Larsen and co-authors ${ }^{45}$ after fermenting 10 different pectins from lemon, orange, lime and sugar beet. However, when comparing only the carbohydrate experiments, POS and SIEM showed statistically similar values, while FOS fermentation resulted in significantly lower numbers than POS in all of these parameters (Tukey's test $p<0.05$ ). Therefore, in this work evidence is provided about a greater effect of POS in comparison with FOS on the improvement of elderly bacterial diversity, that constitutes one of the intervention targets for elderly gut health improvement (as gut microbial diversity was found to be reduced in the elderly population). ${ }^{4}$

To determine the effects of the test products on the overall structure and the beta diversity of the elderly microbiota, a principal coordinate analysis (PCoA) was carried out. Both weighted (Fig. 6a) and unweighted (Fig. 6b) PCoA plots of the microbiota were obtained, where OTU information from toh to $\mathrm{t} 72 \mathrm{~h}$ was included. The three axes explained a total percentage of $84.6 \%$ of the RA variation according to the weighted PCoA and a total of $38.6 \%$ in the unweighted PCoA.

The toh samples clustered very close within both plots, demonstrating that the adaptation period resulted in a very similar microbiota profile with regard to the absolute bacterial abundances (Fig. 6a) and the presence or absence of bacterial species (Fig. 6b), once more confirming the reproducibility of the computer-controlled in vitro model (see also section 3.2). This also supports that the preparation of a standardised
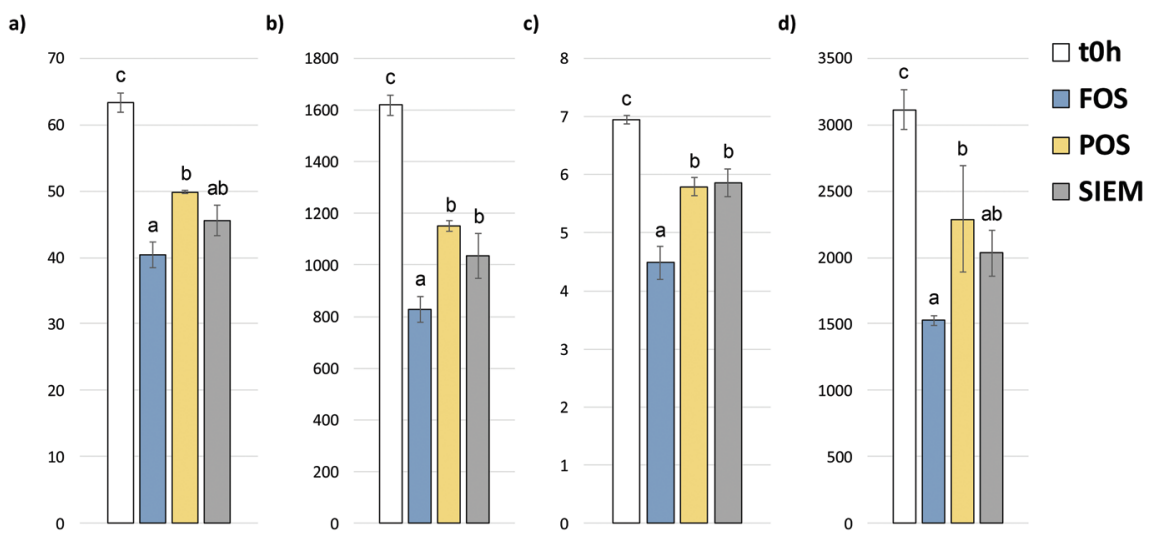

Fig. 5 Average alpha diversity metrics of microbiota at $t=0 \mathrm{~h}$ (toh, $n=5$ ) and after 72 hours ( $n=2$ for each substrate) of in vitro fermentation of FOS, POS and SIEM, rarefied at 21400 sequences per sample. (a) Phylogenetic diversity (whole tree), (b) observed OTUs, (c) Shannon index and (d) Chao1 index. Error bars represent the corresponding standard deviations. Groups sharing the same letter are not significantly different according to Tukey's post hoc tests (significance considered when $p<0.05$ ). FOS, fructooligosaccharides; POS, pectooligosaccharides; SIEM, standard ileal efflux medium. 


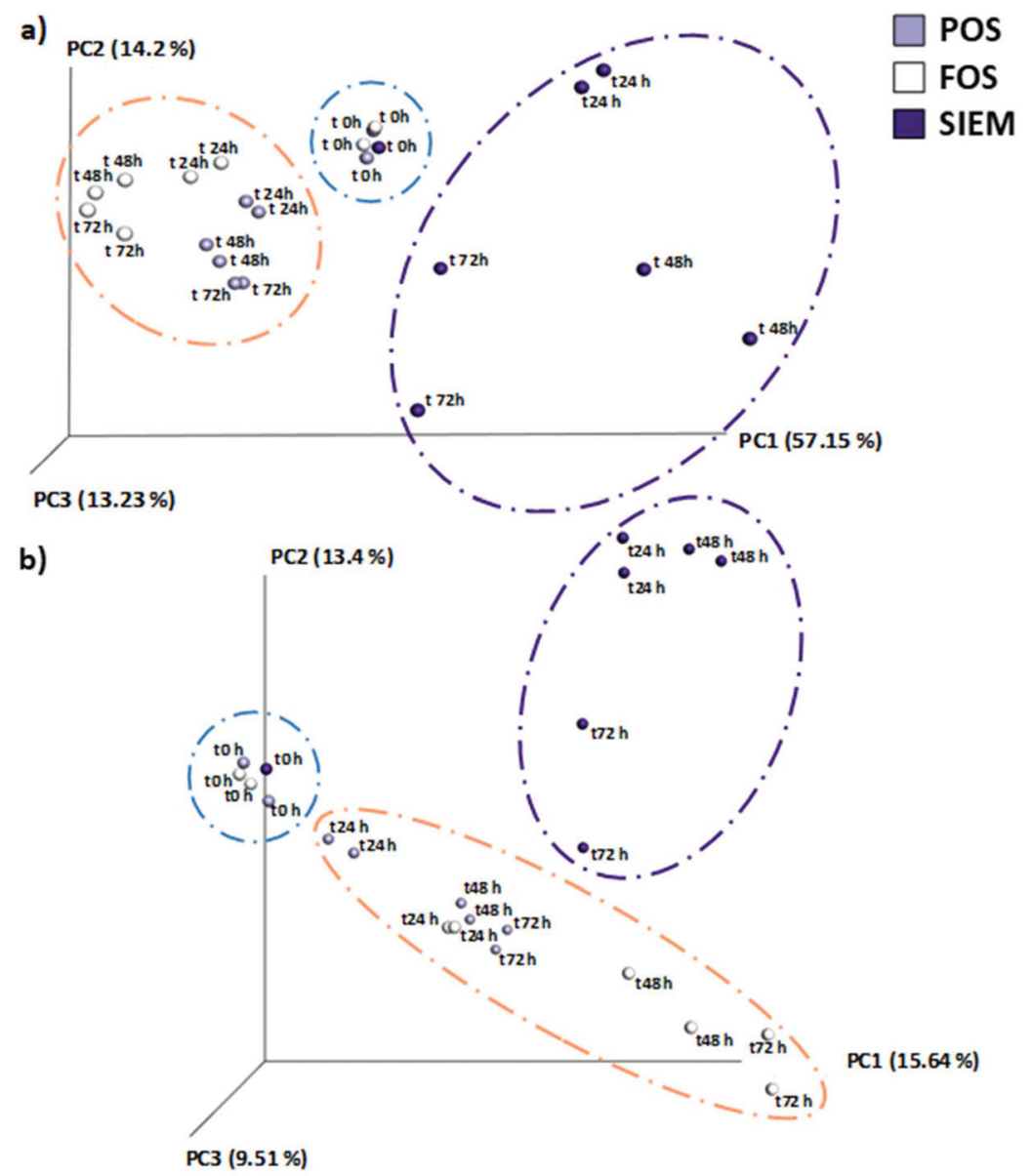

Fig. 6 Beta diversity of microbiota in POS, FOS and SIEM experiments throughout fermentation sampling points (t0-t72h) depicted as (a) weighted PCOA and (b) unweighted PCOA, rarefied at 21400 sequences per sample. Dashed ellipses show substrate clusters found for POS, FOS and SIEM samples, while dashed circle (blue) shows the tOh samples cluster. FOS, fructooligosaccharides; POS, pectooligosaccharides; SIEM, standard ileal efflux medium.

microbiota pool constituted a suitable approach when comparing the effect of different carbohydrates on a certain microbiota profile. Moreover, the formation of clusters also confirms the good reproducibility between duplicate runs for the other time-points (Fig. 6).

In the weighted PCoA (Fig. 6a), it can be observed that POS and FOS promoted similar changes with regard to the community structure (two close clusters can be drawn) confirming the findings discussed in the previous sections (as changes in the weighted PCoA are driven by shifts in dominant taxa) whereas SIEM resulted in a different microbiota. A similar conclusion can be obtained from the unweighted PCoA (Fig. 6b), which is a more "qualitative" representation of the presence/absence of the OTUs in the elderly microbiota, both abundant and minor groups or rare lineages.

\subsection{Production of SCFA, BCFA and other organic acids, and correlations with specific OTUs}

The consumption of carbohydrates in the large intestine is related to the production of a variety of metabolites such as short-chain fatty acids whereas branched-chain fatty acids are associated with the protein fermentation. ${ }^{60}$

In this work, the fermentation of uronic acids, hexoses and pentoses present in some substrates led to the production of different profiles of organic acids. The cumulative production of these acids after $72 \mathrm{~h}$ of fermentation is shown in Fig. 7. As expected, the major products were the SCFA (acetate, propionate and butyrate), followed by other metabolites such as valerate, caproate and succinate. No significant differences were found among POS, FOS or SIEM experiments regarding the cumulative production of butyrate, nor in caproate, formate and lactate or iso-butyrate.

The total SCFA production with POS as the substrate was significantly higher (Tukey's test, $p<0.05$ ) than the one obtained with SIEM $(164.7 \pm 5.6$ and $128.35 \pm 8.2 \mathrm{mmol}$, respectively), while FOS resulted in intermediate values (155.8 \pm 6.1). Previous experiments performed in this system using $7.5 \mathrm{~g}$ day $^{-1}$ of pectin-rich substrates using lean and obese younger subjects and as carbohydrate source apple fibre and sugar beet pectin ${ }^{22}$ or arabinogalactan or inulin ${ }^{61}$ led to lower SCFA values than those achieved with $6.5 \mathrm{~g}$ per day of POS, 


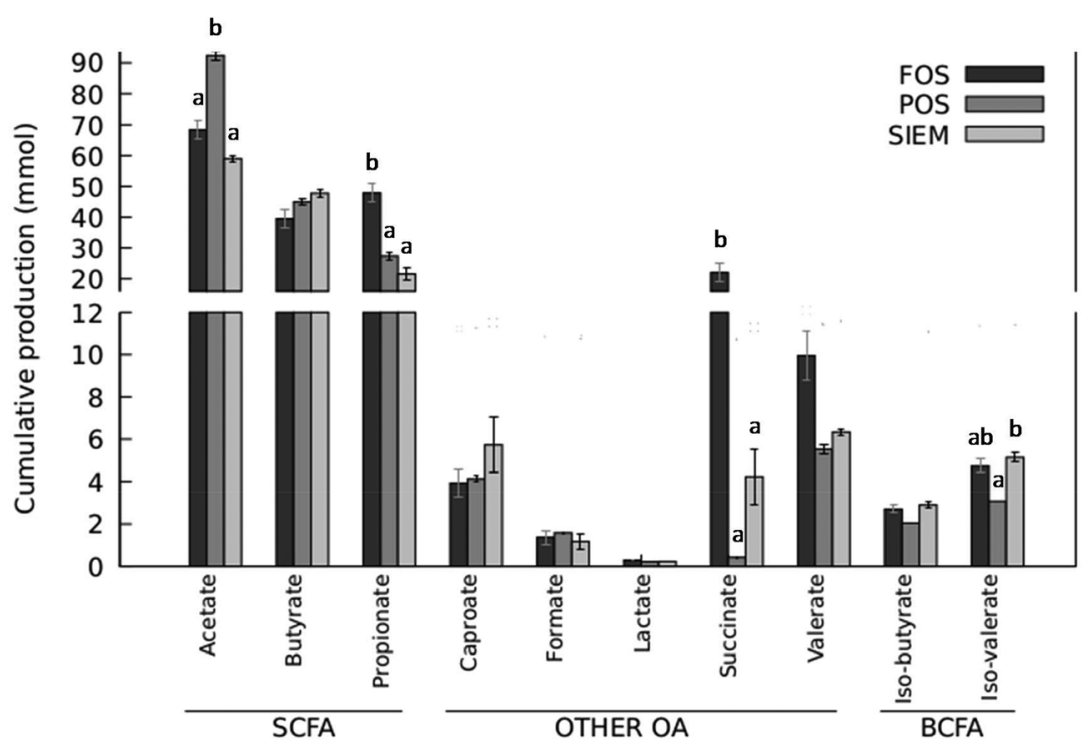

Fig. 7 Average cumulative production of organic acids after $72 \mathrm{~h}$ of fermentation (expressed in mmol). The standard deviation between experiments is represented by the error bars $(n=2)$. Different letters indicate significant differences among substrates for each organic acid according to Tukey's post hoc tests, while acids without a letter are not significantly different according to one-way ANOVA (differences considered significant when $p<$ 0.05 in both cases). BCFA, branched-chain fatty acids; FOS, fructooligosaccharides; OA, organic acids; POS, pectooligosaccharides; SCFA, shortchain fatty acids; SIEM, standard ileal efflux medium.

which makes this POS mixture a promising prebiotic candidate as increases in both total SCFA and butyrate production were previously identified as dietary intervention targets for aged people. ${ }^{4}$ The three SCFA altogether represented 90.7\%, 83.3\% and $77.6 \%$ of the total cumulative organic acids production achieved with POS, SIEM and FOS, respectively.

On the other hand, the acetate : propionate : butyrate molar ratios at $72 \mathrm{~h}$ showed a different profile for each carbohydrate (see Table 3): POS resulted in mixtures containing the major proportion of acetate $(56: 17: 27)$, FOS promoted the highest contents in propionate $(44: 31: 25)$, and SIEM was the most butyratepromoting substrate $(46: 17: 37)$, although as stated above, the differences in butyrate mmol cumulative productions were not significant according to the one-way ANOVA test.

The higher acetate productions upon POS fermentation is a desirable effect as acetate can be used by cross-feeding species to produce butyrate ${ }^{51}$ and it is a co-substrate that might exert a

Table 3 Average ( \pm SD, $n=2$ ) acetate, propionate and butyrate molar ratios obtained after $72 \mathrm{~h}$ of in vitro dynamic fermentation in the TIM-2 system. For each acid, ratio values sharing the same letter among substrates are not significantly different according to Tukey's post hoc tests (significance considered when $p<0.05$ ). FOS, fructooligosaccharides; POS, pectooligosaccharides; SCFA, short-chain fatty acids, SIEM, standard ileal efflux medium

\begin{tabular}{llll}
\hline \multirow{4}{*}{ SCFA } & \multicolumn{4}{l}{ Carbohydrate source } \\
\cline { 2 - 4 } & POS & SIEM & FOS \\
\hline Acetate & $56.08(0.15)^{\mathrm{b}}$ & $46.03(1.50)^{\mathrm{a}}$ & $43.85(2.16)^{\mathrm{a}}$ \\
Propionate & $16.63(0.30)^{\mathrm{a}}$ & $16.73(2.27)^{\mathrm{a}}$ & $30.83(4.86)^{\mathrm{b}}$ \\
Butyrate & $27.29(0.44)^{\mathrm{a}}$ & $37.24(0.77)^{\mathrm{b}}$ & $25.32(2.70)^{\mathrm{a}}$
\end{tabular}

protective effect against pathogens and inflammation, ${ }^{60}$ the latter occurring in the elderly as a chronic low grade inflammatory condition, which can worsen several diseases related to ageing. ${ }^{50}$

In addition, with respect to the BCFA production, no significant differences were found in the iso-butyrate production among the substrates, whereas the cumulative productions of iso-valerate were significantly lower with POS in comparison with SIEM.

Several complex cross-feeding processes are involved in the production of SCFA, and therefore, Spearman correlations were performed between acid concentrations and specific OTUs at the genus-level. The significant correlations found are summarised in Table 4. From the major SCFAs, just acetate showed correlations (all positive, rho $>0$ ), namely with the genera Desulfovibrio, Citrobacter and an unknown genus from the Enterococcaceae family. Although it has been reported that acetate promotes the growth of $F$. prausnitzii, ${ }^{62}$ no correlation was found in this work between acetate and this genus, even though, as discussed above, both LEfSe and RF indicated Faecalibacterium and this specific genus, respectively, as discriminants for POS, which led to the major cumulative acetate levels at $72 \mathrm{~h}$.

Most correlations found involved intermediate acids and BCFA. A wider range of OTUs showed either positive (for instance, Lactobacillus spp.) or negative (for example, Bacteroides or Sutterella) correlations with valerate, whereas the most remarkable correlations with BCFA production, which are produced from branched chain amino acids, ${ }^{63}$ were found for the genera Lactobacillus, Megasphaera and Catenibacterium, which positively correlated with these acids. 
Table 4 Spearman correlations ( $q$ values) found between organic acids and identified OTUs at the genus level. For those OTUs corresponding to unidentified genus (noted as ".g_") or family (".f_"), the taxonomic description includes the closest taxonomic level (family or order, respectively). The presence of green or red arrows indicates whether a positive (rho $>0$ ) or negative (rho $<0$ ) correlation exists, respectively. BCFA, branchedchain fatty acids; $f_{-}$, family; $g_{-}$genus; IA, intermediate acids; SCFA, short-chain fatty acids; $o_{-}$, order

\begin{tabular}{|c|c|c|c|c|c|c|}
\hline \multirow[b]{2}{*}{ Taxa } & \multirow{2}{*}{$\begin{array}{l}\text { SCFA } \\
\text { Acetate }\end{array}$} & \multicolumn{3}{|l|}{ IA } & \multicolumn{2}{|l|}{ BCFA } \\
\hline & & Formate & Lactate & Valerate & Iso-butyrate & Iso-valerate \\
\hline $\begin{array}{l}\mathrm{f} \_ \text {Enterococcaceae.g } \\
\mathrm{g} \text { __Desulfovibrio } \\
\mathrm{g} \text { __Citrobacter } \\
\text { f_Lactobacillaceae.g } \\
\text { g_Lactobacillus } \\
\text { o_Clostridiales }\end{array}$ & $\begin{array}{l}6.017 \\
6.017 \\
6.017\end{array}$ & 6.028 & $\begin{array}{l}9.033 \\
0.025 \\
0.025\end{array}$ & $\begin{array}{l}\text { प0.029 } \\
\text { 10.004 }\end{array}$ & 6.023 & 6.043 \\
\hline $\begin{array}{l}\text { g_Megasphaera } \\
\text { g_Dialister } \\
\text { g__Bacteroides }\end{array}$ & & & Q.035 & $\begin{array}{l}\text { Tho.000 } \\
\text { P0.042 }\end{array}$ & 6.001 & 0.003 \\
\hline $\begin{array}{l}\text { g_Parabacteroides } \\
\text { f_Rikenellaceae.g } \\
\text { g_Butyricimonas }\end{array}$ & & 6.008 & 0.004 & $\begin{array}{l}0.005 \\
0.008 \\
0.049\end{array}$ & $\begin{array}{l}023 \\
0.029\end{array}$ & \\
\hline $\begin{array}{l}\text { o_Bacteroidales.f_.g } \\
\mathrm{f} \_ \text {Erysipelotrichaceae.g } \\
\text { g_Catenibacterium }\end{array}$ & & 0.008 & Q.028 & $\begin{array}{l}0.049 \\
6.004 \\
40.049\end{array}$ & $\begin{array}{l}0.026 \\
0.049\end{array}$ & 0.043 \\
\hline $\begin{array}{l}\text { g_Sutterella } \\
\text { g__Ruminococcus }\end{array}$ & & & Q.010 & $\begin{array}{l}0.017 \\
0.018\end{array}$ & 0.023 & \\
\hline
\end{tabular}

The highest SCFA cumulative productions observed with POS could be of great interest as lower fecal SCFA contents have been detected in the elderly, ${ }^{38}$ as well as in younger elderly. ${ }^{7}$ The role of SCFA in human health has been extensively studied ${ }^{64-66}$ and health benefits of butyrate are well documented, ${ }^{51}$ as it is a metabolite with an important role in the maintenance of the colonic epithelium, ${ }^{66}$ and which might even have potential for brain health improvement. ${ }^{67}$ This would be desirable for elderly people due to the detriment in the cognitive system associated with ageing.

\section{Conclusions}

The results of this work showed that the fermentation of a mixture of pectooligosaccharides obtained from lemon peel waste (POS) in the in vitro colon model TIM-2 resulted in shifts in the elderly microbiota similar to those observed using FOS, usually considered as the gold standard prebiotic. Both substrates showed no significant differences between them regarding the modulation of the major phyla and families, and, for some beneficial genera such as Faecalibacterium (even at species level, $F$. prausnitzii), POS led to higher values in relative abundances. In addition, similar values to those observed at t0 were achieved after POS consumption for other beneficial bacteria such as Blautia whereas they decreased with SIEM or FOS. POS experiments also showed greater alpha diversity values than FOS (a desirable outcome for the elderly population) and the beta-diversity analysis revealed similar microbial profiles for both substrates, which clustered close together in the PCoA. Moreover, although no significant differences were observed among the different carbohydrate interventions with respect to butyrate cumulative production, POS led to the highest SCFA production (SCFA ending up being more than $90 \%$ of the total organic acids produced) and the lowest concentrations of BCFA, two desirable effects for older population health. These results support the potential of POS as food ingredients for the improvement of the gut microbial profiles and its metabolic activity in the elderly, although further research efforts (both in vitro and in vivo assays) will be necessary before using this kind of carbohydrate as a solid strategy for this population.

\section{Abbreviations}

BCFA Branched chain fatty acids

FDR False discovery rate

FOS Fructooligosaccharides

HPLC High performance liquid chromatography

LEfSe Linear discriminant analysis effect size

LPW Lemon peel waste

OTU(s) Operational taxonomic unit(s)

PCoA Principal coordinate analysis

PD Phylogenetic diversity

POS Pectooligosaccharide mixtures

QIIME Quantitative insights into microbial ecology

RA Relative abundance 
RI Refractive index

RF Random forest analysis

SCFA Short chain fatty acids

SIEM Standard ileal efflux medium

TIM-2 TNO intestinal model of the proximal colon

\section{Conflicts of interest}

There are no conflicts of interest to declare.

\section{Acknowledgements}

The authors want to express their gratitude to the Spanish Ministry of Economy and Competitiveness and FEDER program of the European Union (research project "Modified aqueous media for wood biorefineries", reference CTQ201782962-R), Xunta de Galicia (Centro singular de investigación de Galicia, CINBIO, accreditation 2016-2019), the European Union (European Regional Development Fund - ERDF) for supporting this study, and the Dutch Province of Limburg for the subsidy grant to HEFI. B. Míguez also is thankful to Xunta de Galicia for her predoctoral grant. Authors gratefully acknowledge all the support and assistance given by Jessica Verhoeven, Sanne Verbruggen, Rob van Dinter, Cheng Long and the volunteers that provided faecal samples for this study.

\section{References}

1 K. Christensen, G. Doblhammer, R. Rau and J. W. Vaupel, Ageing populations: The challenges ahead, Lancet, 2009, 374, 1196-1208.

2 World Health Organization, Global strategy and action plan on ageing and health, 2017.

3 European Commission, Eurostat, https://ec.europa.eu/ eurostat/en/web/products-eurostat-news/-/DDN-20200402-1, (accessed 17 June 2020).

4 N. Salazar, L. Valdés-Varela, S. González, M. Gueimonde and C. G. de los Reyes-Gavilán, Nutrition and the gut microbiome in the elderly, Gut Microbes, 2017, 8, 82-97.

5 S. J. Clements and S. R. Carding, Diet, the intestinal microbiota, and immune health in aging, Crit. Rev. Food Sci. Nutr., 2016, 8398, 1-11.

6 E. Biagi, M. Candela, S. Turroni, P. Garagnani, C. Franceschi and P. Brigidi, Ageing and gut microbes: perspectives for health maintenance and longevity, Pharmacol. Res., 2013, 69, 11-20.

7 N. Salazar, P. López, L. Valdés, A. Margolles, A. Suárez, Á. M. Patterson, A. Cuervo, C. G. de los Reyes-Gavilán, P. Ruas-Madiedo, S. Gonzalez and M. Gueimonde, Microbial targets for the development of functional foods accordingly with nutritional and immune parameters altered in the elderly, J. Am. Coll. Nutr., 2013, 32, 399-406.
8 S. H. Duncan and H. J. Flint, Probiotics and prebiotics and health in ageing populations, Maturitas, 2013, 75, 44-50.

9 J. M. T. Hamilton-Miller, Probiotics and prebiotics in the elderly, Postgrad. Med. J., 2004, 80, 447-451.

10 D. A. Zema, P. S. Calabrò, A. Folino, V. Tamburino, G. Zappia and S. M. Zimbone, Valorisation of citrus processing waste: A review, Waste Manage., 2018, 80, 252-273.

11 B. Gullón, B. Gómez, M. Martínez-Sabajanes, R. Yáñez, J. C. Parajó and J. L. Alonso, Pectic oligosaccharides: Manufacture and functional properties, Trends Food Sci. Technol., 2013, 30, 153-161.

12 E. Olano-Martin, G. R. Gibson and R. A. Rastall, Comparison of the in vitro bifidogenic properties of pectins and pectic-oligosaccharides, J. Appl. Microbiol., 2002, 93, 505-511.

13 B. Gómez, B. Gullón, R. Yáñez, H. Schols and J. L. Alonso, Prebiotic potential of pectins and pectic oligosaccharides derived from lemon peel wastes and sugar beet pulp: A comparative evaluation, J. Funct. Foods, 2016, 20, 108-121.

14 N. Corzo, J. L. Alonso, F. Azpiroz, M. A. Calvo, M. Cirici, R. Leis, F. Lombó, I. Mateos-Aparicio, F. J. Plou, P. Rúas Madiedo, P. Rupérez, A. Redondo Cuenca, M. L. Sanz and A. Clemente, Prebióticos; Concepto, propiedades y efectos beneficiosos, Nutr. Hosp., 2015, 31, 99-118.

15 B. Míguez, B. Gómez, P. Gullón, B. Gullón and J. L. Alonso, Pectic oligosaccharides and other emerging prebiotics, in Prebiotics and probiotics in human nutrition and health, ed. V. Rao and L. G. Rao, InTechOpen, Croatia, 2016, pp. 301-330.

16 G. R. Gibson, R. Hutkins, M. E. Sanders, S. L. Prescott, R. A. Reimer, S. J. Salminen, K. Scott, C. Stanton, K. S. Swanson, P. D. Cani, K. Verbeke and G. Reid, Expert consensus document: The International Scientific Association for Probiotics and Prebiotics (ISAPP) consensus statement on the definition and scope of prebiotics, Nat. Rev. Gastroenterol. Hepatol., 2017, 14, 491-502.

17 B. Gómez, B. Gullón, R. Yáñez, J. C. Parajó and J. L. Alonso, Pectic oligosacharides from lemon peel wastes: Production, purification, and chemical characterization, J. Agric. Food Chem., 2013, 61, 10043-10053.

18 S. G. Sáyago-Ayerdi, V. M. Zamora-Gasga and K. Venema, Prebiotic effect of predigested mango peel on gut microbiota assessed in a dynamic in vitro model of the human colon (TIM-2), Food Res. Int., 2019, 118, 89-95.

19 M. Cuevas-Tena, A. Alegria, M. J. Lagarda and K. Venema, Impact of plant sterols enrichment dose on gut microbiota from lean and obese subjects using TIM-2 in vitro fermentation model, J. Funct. Foods, 2019, 54, 164-174.

20 K. Venema, The TNO in vitro model of the colon (TIM-2), in The impact of food bioactives on health: In vitro and ex vivo models, ed. K. Verhoeckx, P. Cotter, I. López-Expósito, C. Kleiveland, T. Lea, A. Mackie, T. Requena, D. Swiatecka and H. Wichers, Springer Open, 2015, pp. 293-304.

21 M. Minekus, M. Smeets-Peeters, A. Bernalier, S. MarolBonnin, R. Havenaar, P. Marteau, M. Alric, G. Fonty and J. H. Huis in't Veld, A computer-controlled system to simu- 
late conditions of the large intestine with peristaltic mixing, water absorption and absorption of fermentation products, Appl. Microbiol. Biotechnol., 1999, 53, 108-114.

22 M. Aguirre, D. M. A. E. Jonkers, F. J. Troost, G. Roeselers and K. Venema, In vitro characterization of the impact of different substrates on metabolite production, energy extraction and composition of gut microbiota from lean and obese subjects, PLoS One, 2014, 9, 1-23.

23 A. Maathuis, A. Hoffman, A. Evans, L. Sanders and K. Venema, The effect of the undigested fraction of maize products on the activity and composition of the microbiota determined in a dynamic in vitro model of the human proximal large intestine, J. Am. Coll. Nutr., 2009, 28, 657-666.

24 M. Aguirre, A. Eck, M. E. Koenen, P. H. M. Savelkoul, A. E. Budding and K. Venema, Evaluation of an optimal preparation of human standardized fecal inocula for in vitro fermentation studies, J. Microbiol. Methods, 2015, 117, 78-84.

25 M. Aguirre, J. Ramiro-Garcia, M. E. Koenen and K. Venema, To pool or not to pool? Impact of the use of individual and pooled fecal samples for in vitro fermentation studies, J. Microbiol. Methods, 2014, 107, 1-7.

26 P. Van Den Abbeele, K. Venema, T. Van De Wiele, W. Verstraete and S. Possemiers, Different human gut models reveal the distinct fermentation patterns of arabinoxylan versus inulin, J. Agric. Food Chem., 2013, 61, 98199827.

27 J. G. Caporaso, J. Kuczynski, J. Stombaugh, K. Bittinger, F. D. Bushman, E. K. Costello, N. Fierer, A. G. Peña, J. K. Goodrich, J. I. Gordon, G. A. Huttley, S. T. Kelley, D. Knights, J. E. Koenig, R. E. Ley, C. A. Lozupone, D. McDonald, B. D. Muegge, M. Pirrung, J. Reeder, J. R. Sevinsky, P. J. Turnbaugh, W. A. Walters, J. Widmann, T. Yatsunenko, J. Zaneveld and R. Knight, QIIME allows analysis of high-throughput community sequencing data, Nat. Methods, 2010, 7, 1-12.

28 B. Míguez, C. Vila, K. Venema, J. C. Parajó and J. L. Alonso, Potential of high and low acetylated galactoglucomannooligosaccharides as modulators of the microbiota composition and their activity: A comparison using the in vitro model of the human colon TIM-2, J. Agric. Food Chem., 2020, 68, 7617-7629.

29 N. Segata, J. Izard, L. Waldron, D. Gevers, L. Miropolsky, W. S. Garrett and C. Huttenhower, Metagenomic biomarker discovery and explanation, Genome Biol., 2011, 12, 1-18.

30 M. J. Claesson, S. Cusack, O. O’Sullivan, R. Greene-Diniz, H. de Weerd, E. Flannery, J. R. Marchesi, D. Falush, T. Dinan, G. Fitzgerald, C. Stanton, D. van Sinderen, M. O'Connor, N. Harnedy, K. O'Connor, C. Henry, D. O'Mahony, A. P. Fitzgerald, F. Shanahan, C. Twomey, C. Hill, R. P. Ross and P. W. O'Toole, Composition, variability, and temporal stability of the intestinal microbiota of the elderly, Proc. Natl. Acad. Sci. U. S. A., 2011, 108, 45864591.

31 S. A. Smits, A. Marcobal, S. Higginbottom, J. L. Sonnenburg and P. C. Kashyap, individualized responses of gut microbiota to dietary intervention modeled in humanized mice, mSystems, 2016, 1, 3-8.

32 M. Arumugam, J. Raes, E. Pelletier, D. L. Paslier, T. Yamada, D. R. Mende, G. R. Fernandes, J. Tap, T. Bruls, J.-M. Batto, M. Bertalan, N. Borruel, F. Casellas, L. Fernandez, L. Gautier, T. Hansen, M. Hattori, T. Hayashi, M. Kleerebezem, K. Kurokawa, M. Leclerc, F. Levenez, C. Manichanh, H. B. Nielsen, T. Nielsen, N. Pons, J. Poulain, J. Qin, T. Sicheritz-Ponten, S. Tims, D. Torrents, E. Ugarte, E. G. Zoetendal, J. Wang, F. Guarner, O. Pedersen, W. M. de Vos, S. Brunak, J. Doré, MetaHIT Consortium; M. Antolín, F. Artiguenave, H. M. Blottiere, M. Almeida, C. Brechot, C. Cara, C. Chervaux, A. Cultrone, C. Delorme, G. Denariaz, R. Dervyn, K. U. Foerstner, C. Friss, M. van de Guchte, E. Guedon, F. Haimet, W. Huber, J. van Hylckama-Vlieg, A. Jamet, C. Juste, G. Kaci, J. Knol, O. Lakhdari, S. Layec, K. L. Roux, E. Maguin, A. Mérieux, R. M. Minardi, C. M'rini, J. Muller, R. Oozeer, J. Parkhill, P. Renault, M. Rescigno, N. Sanchez, S. Sunagawa, A. Torrejon, K. Turner, G. Vandemeulebrouck, E. Varela, Y. Winogradsky, G. Zeller, J. Weissenbach, S. D. Ehrlich and P. Bork, Enterotypes of the human gut microbiome, Nature, 2011, 473, 174-180.

33 A. Ntemiri, F. N. Chonchuír, T. F. O’Callaghan, C. Stanton, R. P. Ross and P. W. O'Toole, Glycomacropeptide sustains microbiota diversity and promotes specific taxa in an artificial colon model of elderly gut microbiota, J. Agric. Food Chem., 2017, 65, 1836-1846.

34 H. J. Flint, K. P. Scott, S. H. Duncan, P. Louis and E. Forano, Microbial degradation of complex carbohydrates in the gut, Gut Microbes, 2012, 3, 289-306.

35 E. H. Doo, C. Schwab, C. Chassard and C. Lacroix, Cumulative effect of yeast extract and fructooligosaccharide supplementation on composition and metabolic activity of elderly colonic microbiota in vitro, J. Funct. Foods, 2019, 52, 43-53.

36 C. Bussolo de Souza, M. Jonathan, S. M. Isay Saad, H. A. Schols and K. Venema, Degradation of fibres from fruit by-products allows selective modulation of the gut bacteria in an in vitro model of the proximal colon, J. Funct. Foods, 2019, 57, 275-285.

37 R. Di, M. S. Vakkalanka, C. Onumpai, H. K. Chau, A. White, R. A. Rastall, K. Yam and A. T. Hotchkiss, Pectic oligosaccharide structure-function relationships: prebiotics, inhibitors of Escherichia Coli, O157:H7 adhesion and reduction of shiga toxin cytotoxicity in HT29 cells, Food Chem., 2017, 227, 245-254.

38 N. Salazar, S. Arboleya, T. Fernández-Navarro, C. G. de los Reyes-Gavilán, S. Gonzalez and M. Gueimonde, Age-associated changes in gut microbiota and dietary components related with the immune system in adulthood and old age: A cross-sectional study, Nutrients, 2019, 11, 1-11.

39 A. C. Ouwehand, N. Bergsma, R. Parhiala, S. Lahtinen, M. Gueimonde, H. Finne-Soveri, T. Strandberg, K. Pitkälä and S. Salminen, Bifidobacterium microbiota and para- 
meters of immune function in elderly subjects, FEMS Immunol. Med. Microbiol., 2008, 53, 18-25.

40 M. J. Claesson, I. B. Jeffery, S. Conde, S. E. Power, E. M. O’Connor, S. Cusack, H. M. B. Harris, M. Coakley, B. Lakshminarayanan, O. O'Sullivan, G. F. Fitzgerald, J. Deane, M. O'Connor, N. Harnedy, K. O'Connor, D. O’Mahony, D. van Sinderen, M. Wallace, L. Brennan, C. Stanton, J. R. Marchesi, A. P. Fitzgerald, F. Shanahan, C. Hill, R. P. Ross and P. W. O'Toole, Gut microbiota composition correlates with diet and health in the elderly, Nature, 2012, 488, 178-185.

41 P. Louis and H. J. Flint, Diversity, Metabolism and microbial ecology of butyrate-producing bacteria from the human large intestine, FEMS Microbiol. Lett., 2009, 294, 18.

42 M. Valles-Colomer, G. Falony, Y. Darzi, E. F. Tigchelaar, J. Wang, R. Y. Tito, C. Schiweck, A. Kurilshikov, M. Joossens, C. Wijmenga, S. Claes, L. Van Oudenhove, A. Zhernakova, S. Vieira-Silva and J. Raes, The neuroactive potential of the human gut microbiota in quality of life and depression, Nat. Microbiol., 2019, 4, 623-632.

43 W. D. Taylor, Depression in the elderly, N. Engl. J. Med., 2014, 371, 1228-1236.

44 S. Miquel, R. Martín, O. Rossi, L. G. Bermúdez-Humarán, J. M. Chatel, H. Sokol, M. Thomas, J. M. Wells and P. Langella, Faecalibacterium prausnitzii and human intestinal health, Curr. Opin. Microbiol., 2013, 16, 255-261.

45 N. Larsen, C. B. De Souza, L. Krych, T. B. Cahú, M. Wiese, W. Kot, K. M. Hansen, A. Blennow, K. Venema and L. Jespersen, Potential of pectins to beneficially modulate the gut microbiota depends on their structural properties, Front. Microbiol., 2019, 10, 233.

46 B. Gómez, B. Gullón, C. Remoroza, H. A. Schols, J. C. Parajó and J. L. Alonso, Purification, characterization, and prebiotic properties of pectic oligosaccharides from orange peel wastes, J. Agric. Food Chem., 2014, 62, 97699782.

47 M. Lopez-Siles, T. M. Khan, S. H. Duncan, H. J. M. Harmsen, L. J. Garcia-Gil and H. J. Flint, Cultured representatives of two major phylogroups of human colonic faecalibacterium prausnitzii can utilize pectin, uronic acids, and host-derived substrates for growth, Appl. Environ. Microbiol., 2012, 78, 420-428.

48 S. Bartosch, A. Fite, G. T. Macfarlane and M. E. T. Mcmurdo, Characterization of bacterial communities in feces from healthy elderly volunteers and hospitalized elderly patients by using real-time pcr and effects of antibiotic treatment on the fecal microbiota, Appl. Environ. Microbiol., 2004, 70, 3575-3581.

49 H. Sokol, B. Pigneur, L. Watterlot, O. Lakhdari, L. G. Bermúdez-Humarán, J. J. Gratadoux, S. Blugeon, C. Bridonneau, J. P. Furet, G. Corthier, C. Grangette, N. Vasquez, P. Pochart, G. Trugnan, G. Thomas, H. M. Blottière, J. Doré, P. Marteau, P. Seksik and P. Langella, Faecalibacterium prausnitzii is an anti-inflammatory commensal bacterium identified by gut microbiota analysis of crohn disease patients, Proc. Natl. Acad. Sci. U. S. A., 2008, 105, 16731-16736.

50 P. C. Calder, N. Bosco, R. Bourdet-Sicard, L. Capuron, N. Delzenne, J. Doré, C. Franceschi, M. J. Lehtinen, T. Recker, S. Salvioli and F. Visioli, Health relevance of the modification of low grade inflammation in ageing (inflammageing) and the role of nutrition, Ageing Res. Rev., 2017, 40, 95-119.

51 A. Rivière, M. Selak, D. Lantin, F. Leroy and L. De Vuyst, Bifidobacteria and butyrate-producing colon bacteria: Importance and strategies for their stimulation in the human gut, Front. Microbiol., 2016, 7, 979.

52 A. Kageyama and Y. Benno, Catenibacterium mitsuokai gen. nov., sp. nov., a Gram-positive anaerobic bacterium isolated from human faeces, Int. J. Syst. Evol. Microbiol., 2000, 50, 1595-1599.

53 A. Barcenilla, S. E. Pryde, J. C. Martin, S. H. Duncan, C. S. Stewart, C. Henderson and H. J. Flint, Phylogenetic relationships of butyrate-producing bacteria from the human gut, Appl. Environ. Microbiol., 2000, 66, 1654-1661.

54 G. D. Wu, J. Chen, C. Hoffmann, K. Bittinger, Y. Y. Chen, S. A. Keilbaugh, M. Bewtra, D. Knights, W. A. Walters, R. Knight, R. Sinha, E. Gilroy, K. Gupta, R. Baldassano, L. Nessel, H. Li, F. D. Bushman and J. D. Lewis, Linking long-term dietary patterns with gut microbial enterotypes, Science, 2011, 334, 105-108.

55 S. Heinzel, V. T. E. Aho, U. Suenkel, A. K. von Thaler, C. Schulte, C. Deuschle, L. Paulin, S. Hantunen, K. Brockmann, G. W. Eschweiler, W. Maetzler, D. Berg, P. Auvinen and F. Scheperjans, Gut microbiome signatures of risk and prodromal markers of parkinson disease, Ann. Neurol., 2020, 88, 320-331.

56 A. W. Willis, Parkinson disease in the elderly adult, Mo. Med., 2013, 110, 406-410.

57 E. Britton and J. T. Mclaughlin, Conference on 'Malnutrition matters' Nutrition Society Symposium: Muscle wasting with age: A new challenge in nutritional care; Part 1 - the underlying factor (Ageing and the gut), Proc. Nutr. Soc., 2013, 72, 173-177.

58 P. Louis and H. J. Flint, Formation of propionate and butyrate by the human colonic microbiota, Environ. Microbiol., 2017, 19, 29-41.

59 B. R. Kim, J. Shin, R. B. Guevarra, J. H. Lee, D. W. Kim, K. H. Seol, J. H. Lee, H. B. Kim and R. E. Isaacson, Deciphering diversity indices for a better understanding of microbial communities, J. Microbiol. Biotechnol., 2017, 27, 2089-2093.

60 W. R. Russell, L. Hoyles, H. J. Flint and M. E. Dumas, Colonic bacterial metabolites and human health, Curr. Opin. Microbiol., 2013, 16, 246-254.

61 M. Aguirre, C. Bussolo De Souza and K. Venema, The gut microbiota from lean and obese subjects contribute differently to the fermentation of arabinogalactan and inulin, PLoS One, 2016, 11, 1-18.

62 S. H. Duncan, G. L. Hold, H. J. M. Harmsen, C. S. Stewart and H. J. Flint, Growth requirements and fermentation pro- 
ducts of Fusobacterium prausnitzii, and a proposal to reclassify it as Faecalibacterium prausnitzii gen. nov., comb. nov, Int. J. Syst. Evol. Microbiol., 2002, 52, 2141-2146.

63 W. R. Russell, S. W. Gratz, S. H. Duncan, G. Holtrop, J. Ince, L. Scobbie, G. Duncan, A. M. Johnstone, G. E. Lobley, R. J. Wallace, G. G. Duthie and H. J. Flint, High-protein, reduced-carbohydrate weight-loss diets promote metabolite profiles likely to be detrimental to colonic health, Am. J. Clin. Nutr., 2011, 93, 10621072.

64 G. Den Besten, K. Van Eunen, A. K. Groen, K. Venema, D. J. Reijngoud and B. M. Bakker, The role of short-chain fatty acids in the interplay between diet, gut microbiota, and host energy metabolism, J. Lipid Res., 2013, 54, 23252340 .

65 A. Koh, F. De Vadder, P. Kovatcheva-Datchary and F. Bäckhed, From dietary fiber to host physiology: shortchain fatty acids as key bacterial metabolites, Cell, 2016, 165, 1332-1345.

66 D. J. Morrison and T. Preston, Formation of short chain fatty acids by the gut microbiota and their impact on human metabolism, Gut Microbes, 2016, 7, 189-200.

67 M. W. Bourassa, I. Alim, S. J. Bultman and R. R. Ratan, Butyrate, neuroepigenetics and the gut microbiome: Can a high fiber diet improve brain health?, Neurosci. Lett., 2016, 625, 56-63. 